\title{
Cannibalism and intraguild predation in clupeoids
}

\author{
Edy Valdés Szeinfeld
}

Sea Fisheries Research Institute, Private Bag X2, 8012 Rogge Bay, Cape Town

and

Marine Biology Research Institute, University of Cape Town, Private Bag, 7700 Rondebosch, Cape Town, South Africa

\begin{abstract}
This paper provides empirical data of anchovy egg mortality caused by cannibalism and sardine predation. Rates of anchovy egg mortality during the period 1986 to 1988 averaged ca $0.01 \mathrm{~h}^{-1}$, representing a survival rate of about $55 \%$ over the $60 \mathrm{~h}$ incubation period. Some $56 \%$ of 3325 anchovy stomachs and some $88 \%$ of 1225 sardine stomachs in samples collected during the period 1986 to 1988 contained anchovy eggs. Of 750 sardines and anchovies caught in co-habited areas during this period, $67 \%$ of the anchovy and $87 \%$ of the sardine had anchovy eggs in their stomachs. Mean numbers of eggs observed in stomachs per $\mathrm{kg}$ of fish mass of the co-occurrent collections were 24 in anchovies and 2117 in sardines. It was estimated that up to $56 \%$ of the total anchovy egg mortality was the result of sardine predation and up to $6 \%$ was the result of anchovy cannibalism. Fluctuations in anchovy recruitment and cycles in the abundance of clupeoid species in the Benguela system are likely to be attributable at least in part to these 2 mechanisms.
\end{abstract}

\section{INTRODUCTION}

A guild of planktivorous clupeoid species comprising the Cape anchovy Engraulis capensis and the South African pilchard or sardine Sardinops ocellatus is harvested by the South African purse-seine fishery. The 2 species combined yielded more than 2 million tons from 1984 to 1988 . The fishery has been characterized by a 'boom and bust' phenomenon of shifts in the distribution of both guild species over the years (Shannon et al. 1988), as has happened with similar clupeoid species in similar ecosystems around the world (Lasker \& MacCall 1983).

Species interactions involving predation are a major topic of discussion in fisheries. Predator-prey interdependence has been postulated as a possible cause of 'cycles' in abundance in guild species (Walters et al. 1986, Polis et al. 1989). Cannibalism has been proposed as a mechanism providing an upper limit to population density (Ricker 1958, 1973, Hunter \& Kimbrell 1980, MacCall 1981, Alheit 1987, Valdes et al. 1987) of filter-feeding, pelagic-spawning, schooling coastal pelagic fish such as clupeoids. In other words, cannibalism can cause population self-regulation. On the other hand, predation by guild species may 'regulate' the total biomass of competing species (Fox 1975).
Population stabilization through compensating cannibalism is possible if predator abundance is constant and they have a sigmoid (Type III) functional response to prey density (Holling 1959, Murdoch 1969, Peterman \& Gatto 1978). Increasing mortality may result if prey density increases and prey switching behaviour and/or numerical response increases (Murdoch 1969, Murdoch et al. 1975).

In theory, density-dependent regulation might occur at any stage, including the egg (MacCall 1981, Valdés et al. 1987). However, density-independent factors tend to mask the relatively weak density-dependent influences (MacCall 1981, Welch 1986).

In this paper it is postulated that if cannibalism occurs together with intraguild predation, both may cause a synergistic effect reinforcing the possibility of long-term shifts in the relative abundance of sardine and anchovy in the Benguela system. In this open system, nonequilibrium behaviour (i.e. cyclical variations in the stock sizes of both species) may persist for long periods (Caswell 1978).

This paper provides empirical evidence on anchovy cannibalism and sardine predation and shows that anchovy egg mortality rates may change as a result of interactions between the guild species. Several parameters which may interact to determine rate of intra- 
specific or interspecific predation on anchovy eggs from 1986 to 1988 will be considered.

\section{MATERIALS AND METHODS}

Fish and plankton samples were collected off the South African coast during research cruises of the Sea Fisheries Research Institute's (SFRI) RS 'Africana' in November 1986, 1987 and 1988. Survey design has been described and illustrated in Armstrong et al. (1988), and therefore only a brief account is given here.

The investigation encompassed the spawning grounds of anchovy off South Africa on an intensive grid of plankton stations normally spaced $9.3 \mathrm{~km}$ apart. At each station anchovy eggs were sampled by means of vertical hauls of a CalVETnet (Smith et al. 1985) from $200 \mathrm{~m}$ deep or, when the bottom depth was $<200 \mathrm{~m}$, from as near the sea bed as possible. Temperature and depth profiles were obtained by means of a temperature probe and depth sensor attached below the CalVET net. Egg abundance was converted to number per $\mathrm{m}^{2}$ at sea surface. It was assumed that this was directly proportional to the number per $\mathrm{m}^{3}$ because Shelton (1986) showed the vertical distribution of anchovy eggs to be fairly uniform within the region of the upper mixed layer inhabited by anchovy. The design of the CalVET net makes clogging unlikely within a tow (Smith et al. 1985). Thus, the use of a flowmeter was not required to verify the constant filtration of water per unit depth. In areas of zero egg abundance, the distance between stations was frequently increased to $18.6 \mathrm{~km}$.

Immediately after the completion of each tow, the plankton sample was fixed in $4 \%$ buffered formaldehyde in seawater. In the laboratory, anchovy eggs were removed from the plankton samples under a binocular dissecting microscope at $20 \times$ magnification. Based on the degree of embryonic development, and following the method of Moser \& Alhstrom (1985), eggs were assigned to 11 stages as described by Valdes et al. (1987). The abundance per $\mathrm{m}^{2}$ of each stage in the samples was calculated. Peak spawning time was determined from the time of day at which newly fertilized eggs appeared in the egg collection and from observations of the occurrence of hydrated eggs in the ovaries of adult fish. The age of the eggs was determined to permit calculation of egg mortality and production rates. Methods used are fully described in Armstrong et al. (1988).

Adult anchovy and sardine were caught by means of a midwater trawl deployed, whenever possible, immediately preceding or following the CalVET net dip. A total of 182 trawl samples were analysed over the 3 years and 25 fish of each species (sardine and anchovy) were taken from each trawl sample and immediately blast-frozen (a total of 4550 fish, 3325 anchovy and 1225 sardine). In the laboratory, all fish were weighed, their stomachs removed and the number of anchovy eggs in each stomach determined.

\section{RESULTS}

Anchovy were caught in 60 and sardine in 47 of the 68 midwater trawls taken in 1986, anchovy in 62 and sardine in 46 of the 72 trawls in 1987, andanchovy in 41 and sardine in 28 of the 63 trawls in 1988. Of the 3325 anchovy analysed for presence and number of anchovy eggs in their stomachs, 950 were caught in 1986, 1550 in 1987 and 825 in 1988. On average $56 \%$ of the anchovy samples contained anchovy eggs. Of the 1225 sardine stomachs analysed (500 from 1986, 350 from 1987 and 375 from 1988), an average $88 \%$ contained anchovy eggs. Further, from the total number of trawl samples available for this study, only 14 trawls for 1986, 7 trawls for 1987 and 9 trawls for 1988 were found in which anchovy and sardine occurred together. In those samples, $67 \%$ of the anchovy and $87 \%$ of the sardine had anchovy eggs in their stomachs (Table 1 ).

The number of anchovy eggs found in anchovy stomachs during 1986, taken to be an index of cannibalism on their own eggs, is shown in Fig. 1a. The same figure also shows anchovy egg distribution, monitored by plankton sampling. Fig. 1b shows anchovy distribution, determined by acoustics and validated by midwater trawling. Fig. 2 contains similar data for the sardine: Fig. 2a shows the anchovy egg distribution monitored by CalVET net sampling and intensity of cannibalism. Fig. $2 \mathrm{~b}$ shows the distribution of adult sardine monitored by acoustics. Figs. $1 \& 2$ both suggest that the degree of predation can be directly related to the degree of overlapping between the distributions of the fish and the eggs. Figs. 1 \& 2 also suggest that predation is highest when fish distribution overlaps the areas of greatest egg abundance.

Table 1 summarizes the number of anchovy eggs found per fish stomach in areas of co-occurrence of both species during 1986, 1987 and 1988. In order to correct for the different sizes of anchovy and sardine and to compare the data of the 2 species on a weightto-weight basis, the average number of eggs in the fish stomachs was calculated per $\mathrm{kg}$ wet fish mass. For anchovy in 1986, each $1 \mathrm{~kg}$ of fish contained 18 anchovy eggs, but $1 \mathrm{~kg}$ of sardine contained 2 orders of magnitude more eggs (i.e. 1988 eggs). During 1987, $1 \mathrm{~kg}$ of anchovy and sardine contained 58 and 549 
Table 1. Engraulis capensis. Mean number of anchovy eggs in stomachs of anchovy and sardine per $1 \mathrm{~kg}$ wet fish mass at trawl stations in November 1986, 1987 and 1988 where anchovy co-occurred with sardine

\begin{tabular}{|c|c|c|c|c|c|c|c|c|}
\hline \multicolumn{3}{|c|}{1986} & \multicolumn{3}{|c|}{1987} & \multicolumn{3}{|c|}{1988} \\
\hline Station & Anchovy & Sardine & Station & Anchovy & Sardine & Station & Anchovy & Sardine \\
\hline $01-03$ & 0 & 16 & $01-11$ & 0 & 4 & 09-11 & 7 & 1473 \\
\hline $06-05$ & 22 & 21 & $01-15$ & 20 & 51 & 09-13 & 1 & 6 \\
\hline $07-03$ & 62 & 294 & $02-09$ & 0 & 9 & $19-07$ & 0 & 3296 \\
\hline $11-01$ & 3 & 109 & $02-20$ & 35 & 2670 & $20-07$ & 3 & 42 \\
\hline $14-01$ & 0 & 53 & $04-14$ & 0 & 0 & $20-08$ & 10 & 10909 \\
\hline $14-05$ & 23 & 131 & $16-01$ & 5 & 1089 & $21-06$ & 31 & 7111 \\
\hline $15-06$ & 89 & 525 & $51-05$ & 347 & 21 & $35-03$ & 0 & 109 \\
\hline $23-05$ & 15 & 0 & & & & $41-09$ & 4 & 8896 \\
\hline $27-12$ & 10 & 105 & & & & $43-09$ & 10 & 0 \\
\hline $30-07$ & 0 & 1014 & & & & & & \\
\hline $32-07$ & 0 & 21 & & & & & & \\
\hline $37-06$ & 0 & 1655 & & & & & & \\
\hline $38-07$ & 0 & 5818 & & & & & & \\
\hline $39-02$ & 22 & 18069 & & & & & & \\
\hline Mean & 17.6 & 1987.9 & & 58.1 & 549.1 & & 6.6 & 3189.2 \\
\hline
\end{tabular}

anchovy eggs respectively, and in 1988, each $\mathrm{kg}$ of anchovy and sardine contained 7 and 3189 anchovy eggs respectively in their stomachs.

The number of anchovy eggs consumed cannibalistically and by sardine predation was calculated according to the equation used by Hunter \& Kimbrell (1980) for the northern anchovy Engraulis mordax, by Santander et al. (1983) and Alheit (1987) for the Peruvian anchovy E. ringens and by Valdés et al. (1987) for the Cape anchovy. Thus,

$$
C=E E \cdot g \cdot t
$$

where $C=$ mean number of eggs eaten per $\mathrm{kg}$ of fish during time $t ; E E=$ mean number of eggs observed per $\mathrm{kg}$ of predator stomach; $t=$ duration of feeding (h) and $g=$ gastric evacuation rate.

Although Eq. (1) is derived assuming a steady state between ingestion and gastric evacuation during time $t$, and there was indeed an apparent trend in egg consumption with time (Armstrong et al. in press), it does provide a simple method for calculating the number of eggs eaten and allows comparison with estimated values found according to the same methodology in other ecosystems. Furthermore, although the anchovy diel feeding cycle exhibits 2 peaks, one at dawn and one at dusk (Armstrong et al. in press), fewer fish caught during daylight were available for analysis than fish taken at night. Therefore, the average number of anchovy eggs determined per predator stomach over $24 \mathrm{~h}$ of sampling was used as an index for comparison. Santander et al. (1983) and Alheit (1987) also considered indices over $24 \mathrm{~h}$ of feeding and calculated the average consumption over this period despite the Peruvian anchovy having only a single feeding peak, at midnight (Jarre et al. 1991). The hourly instantaneous rate of gastric evacuation was assumed to be $0.701 \mathrm{~h}^{-1}$ as estimated by Hunter \& Kimbrell (1980) for northern anchovy feeding on anchovy eggs.

Therefore, from the data on egg abundance per $1 \mathrm{~kg}$ of predators (mean egg consumption per $\mathrm{kg}$ of anchovy and sardine $=32.7,1058 ; 42.8,739 ; 15.3,3537$ for 1986 , 1987 and 1988, respectively) and the relationship given in Eq. (1), the average daily consumption of anchovy eggs by $1 \mathrm{~kg}$ of adult anchovy was calculated as 550, 720 and 258 eggs for 1986, 1987 and 1988 respectively (Table 2). Daily sardine predation on anchovy eggs was also estimated by means of Eq. (1) and assumed the same rate of gastric evacuation of anchovy eggs (i.e. $0.701 \mathrm{~h}^{-1}$ ). The average number of eggs eaten daily per $\mathrm{kg}$ of sardine was 17800,12433 and 59516 eggs for 1986,1987 and 1988 , respectively (Table 2).

The proportion of egg mortality caused by intraspecific and interspecific predation by anchovy and sardine on anchovy eggs during the $60 \mathrm{~h}$ period prior to hatching was calculated according to the method given by Hunter \& Kimbrell (1980), but including the modification introduced by MacCall (1981) and used by Santander et al. (1983) and Alheit (1987) for the Peruvian anchovy, and by Valdés et al. (1987) for the Cape anchovy:

$$
P_{\mathrm{c}}=Z_{\mathrm{c}} / Z_{\mathrm{t}}=\left(C_{\mathrm{t}} / G_{\mathrm{t}}\right) /\left(1-\mathrm{e}^{-t Z}\right)
$$

where $Z_{c}=$ proportion of egg production consumed by cannibalism or sardine predation $\left(C_{\mathrm{t}} / G_{\mathrm{t}}\right) ; C_{\mathrm{t}}=$ daily total anchovy egg consumption by anchovy or sardine; $G_{\mathrm{t}}=$ total daily anchovy egg production; $Z_{\mathrm{t}}=$ 


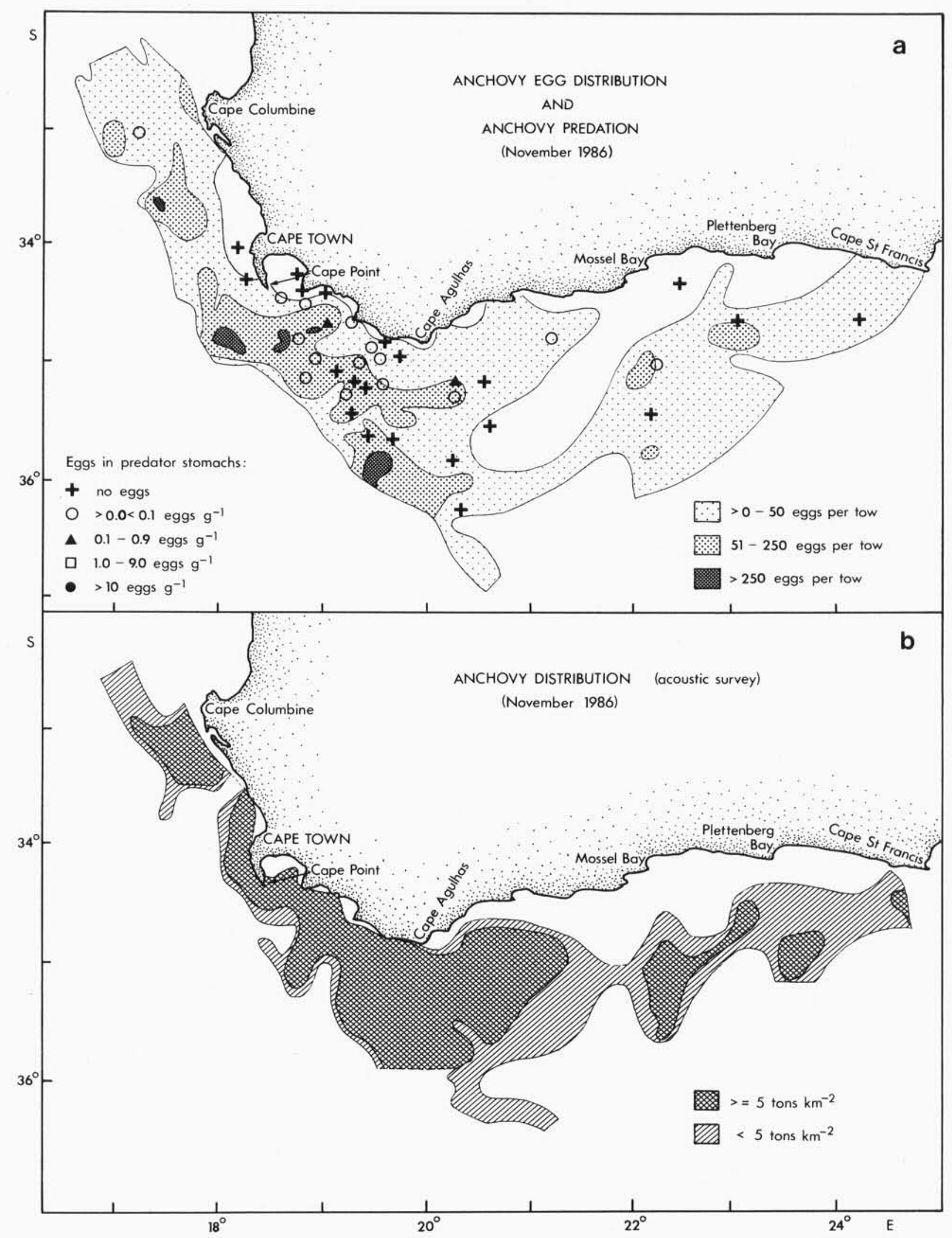

Fig. 1. (a) Engraulis capensis. Anchovy egg distribution monitored by CalVET net sampling and places where cannibalism occurred. (b) Distribution of adult fish monitored by acoustics 


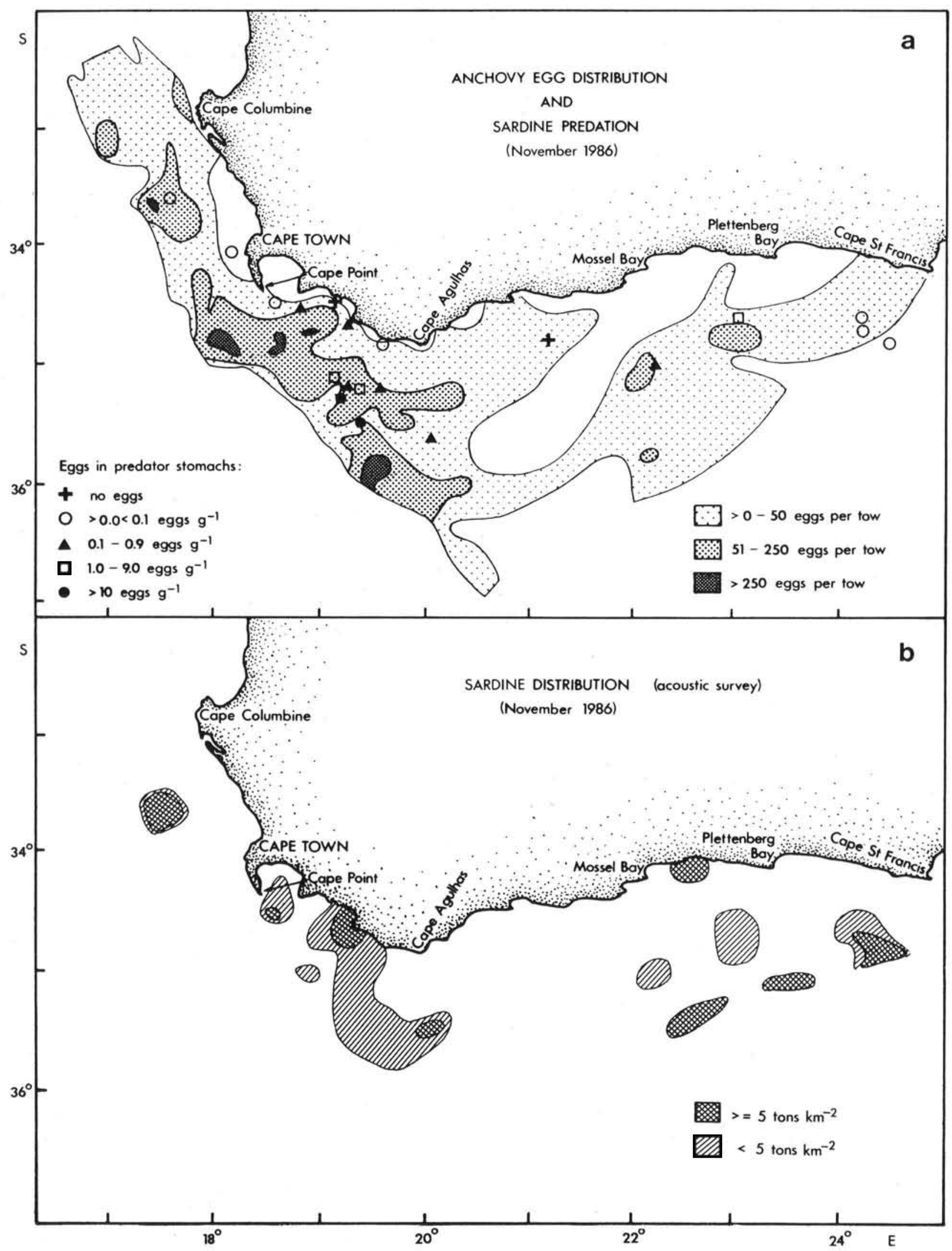

Fig. 2. (a) Engraulis capensis. Anchovy egg distribution monitored by CalVET net sampling and places where predation occurred. (b) Sardinops ocellatus. Distribution of sardine monitored by acoustics 
Table 2. Parameters, their values and results of calculations to estimate daily predator egg consumption and percentage of total anchovy egg mortality due to egg cannibalism and sardine predation (values for $W, R, S, B, Z$ in 1986 are taken from Armstrong et al. (1988), while those for 1987 and 1988 are taken from unpublished SFRI records)

\begin{tabular}{|c|c|c|c|c|c|c|}
\hline \multirow[t]{2}{*}{ Parameter } & \multicolumn{2}{|c|}{1986} & \multicolumn{2}{|c|}{1987} & \multicolumn{2}{|c|}{1988} \\
\hline & Anchovy & Sardine & Anchovy & Sardine & Anchovy & Sardine \\
\hline $\begin{aligned} W= & \text { Average fish } \\
& \text { weight }(\mathrm{kg})\end{aligned}$ & 0.011700 & & 0.011066 & & 0.012024 & \\
\hline $\begin{aligned} F= & \text { Average no. of } \\
& \text { eggs spawned } \\
& \text { per female }\end{aligned}$ & 5627 & & 6490 & & 5878 & \\
\hline$R=$ Sex ratio & 0.5530 & & 0.5609 & & 0.5446 & \\
\hline $\begin{aligned} S= & \text { Average fraction } \\
& \text { of females } \\
& \text { spawning per day }\end{aligned}$ & 0.0950 & & 0.0801 & & 0.0845 & \\
\hline $\begin{aligned} B= & \text { Biomass from } \\
& \text { acoustics }(\mathrm{kg})\end{aligned}$ & $1.747 \times 10^{9}$ & $1.600 \times 10^{8}$ & $1.460 \times 10^{9}$ & $1.270 \times 10^{8}$ & $1.106 \times 10^{9}$ & $1.170 \times 10^{8}$ \\
\hline $\begin{aligned} Z= & \text { Instantaneous } \\
& \text { mortality rate } \\
& \text { for anchovy eggs }\end{aligned}$ & 0.0115 & & 0.0115 & & 0.0165 & \\
\hline $\begin{aligned} C= & \text { Average anchovy } \\
& \text { eggs eaten daily } \\
& \text { per } \mathrm{kg} \text { of predator }\end{aligned}$ & 550 & 17800 & 720 & 12433 & 258 & 59516 \\
\hline $\begin{aligned} C_{l}= & \text { Total anchovy } \\
& \text { eggs eaten } \\
& \text { daily }(C \times B)\end{aligned}$ & $10 \times 10^{11}$ & $28 \times 10^{11}$ & $10.5 \times 10^{11}$ & $16 \times 10^{11}$ & $3 \times 10^{11}$ & $7 \times 10^{12}$ \\
\hline $\begin{aligned} G= & \text { Total daily } \\
& \text { anchovy egg produc- } \\
& \text { tion per kg anchovy } \\
& (F \times R \times S) / \mathrm{W}\end{aligned}$ & 25266 & & 26349 & & 22497 & \\
\hline $\begin{aligned} G_{\mathrm{t}}= & \text { Total daily } \\
& \text { anchovy egg pro- } \\
& \text { duction }(G \times B)\end{aligned}$ & $4.4 \times 10^{13}$ & & $3.8 \times 10^{13}$ & & $2.5 \times 10^{13}$ & \\
\hline $\begin{aligned} Z_{\mathrm{c}}= & \text { Proportion of } \\
& \text { anchovy egg pro- } \\
& \text { duction consumed } \\
& \text { by cannibalism or } \\
& \text { sardine predation } \\
& \left(C_{\mathrm{t}} / G_{\mathrm{t}}\right)\end{aligned}$ & 0.02 & 0.06 & 0.03 & 0.04 & 0.01 & 0.28 \\
\hline $\begin{aligned} P_{\mathrm{c}}= & \text { Proportion of } \\
& \text { anchovy egg } \\
& \text { mortality caused } \\
& \text { by anchovy or } \\
& \text { sardine predation }\end{aligned}$ & 0.04 & 0.12 & 0.06 & 0.08 & 0.02 & $0.44-0.56^{\mathrm{a}}$ \\
\hline
\end{tabular}

proportion of egg production lost due to all causes of mortality $\left(1-\mathrm{e}^{-t Z}\right) ; Z=$ hourly instantaneous rate of egg mortality; and $t=60 \mathrm{~h}$.

Results of calculations to estimate daily egg consumption by predators and percentage of total egg mortality inflicted by cannibalism and sardine predation are given in Table 2. $P_{\mathrm{c}}$ values for 1986 were also estimated empirically by Monte Carlo simulation using standard error of $E E$ and also the standard error of $Z$ as fully described in Valdés et al. (1987). Both estimates (Table 2) and empirical values provided the same information: namely $12 \%$ of the total anchovy egg mortality was caused by sardine predation and $4 \%$ by cannibalism (values were significantly different, $p<0.05)$. Results also indicated that whereas sardine predation caused only $12 \%$ of the total anchovy egg mortality in 1986, this percentage increased to $56 \%$ in 1988. 


\section{DISCUSSION}

The phenomenon of anchovy egg predation by a guild clupeoid species is not unique to the Benguela system. Santander et al. (1983) and Alheit (1987) reported that predation by Pacific sardine Sardinops sagax on anchovy eggs had a greater effect on egg mortality than did anchovy egg cannibalism itself.

Hunter \& Kimbrell (1980) estimated that $32.4 \%$ of the egg mortality of the northern anchovy could be attributed to egg cannibalism, although applying MacCall's (1981) modification the value would be $28 \%$. Alheit (1987) has calculated a similar percentage (i.e. $22 \%$ ) for the Peruvian anchovy. For the Benguela system, Valdés et al. (1987) estimated that egg cannibalism by anchovy could cause an average of $70 \%$ of total anchovy egg mortality at specific sites of high egg density. Nevertheless, in this paper it was shown that, at stations where guild clupeoid species co-occur, sardine predation potentially accounts for more of the anchovy egg mortality than cannibalism does.

Data from the Peruvian system showed that whereas $1 \mathrm{~kg}$ of anchovy had on average 335 eggs in the stomach, $1 \mathrm{~kg}$ of sardines contained more than double, 757 eggs (Alheit 1987). Comparing this with data from the Benguela system (Table 1), it is noticeable that the average number of anchovy eggs found per $\mathrm{kg}$ of adult anchovy is up to 2 orders of magnitude lower in the Benguela than in the Peruvian system, whereas predation by sardines, as reflected by the number of eggs found in fish stomachs, is up to 1 order of magnitude higher in the Benguela.

Both feeding periodicity and anchovy diet at spawning (Valdés et al. 1987, Armstrong et al. in press) suggest that anchovy eggs are a substantial source of food for Engraulis capensis. The rapid digestion rate of anchovy eggs by the northern anchovy (they become digested and unrecognizable at a rate of $50 \% \mathrm{~h}^{-1}$; Hunter \& Kimbrell 1980) emphasizes that even relatively small numbers of eggs recorded in the stomachs of a fish may represent a substantial daily egg consumption. However, the factor regulating egg consumption by anchovy would likely be the functional response to egg density at specific sites (Valdes et al. 1987).

The functional relationship between egg density and egg consumption rate by individual anchovies, based on the work of Valdés (1986) and Valdés et al. (1987), is given in Fig. 3. Given the similar feeding behaviour of the sardine to the anchovy, the same relationship may also apply to the sardine. The relationship that emerges from comparing the stomach of midwater trawl samples of clupeoids and nearby plankton samples suggests an exponential relationship, as a part of an S-shaped curve, between the number of anchovy

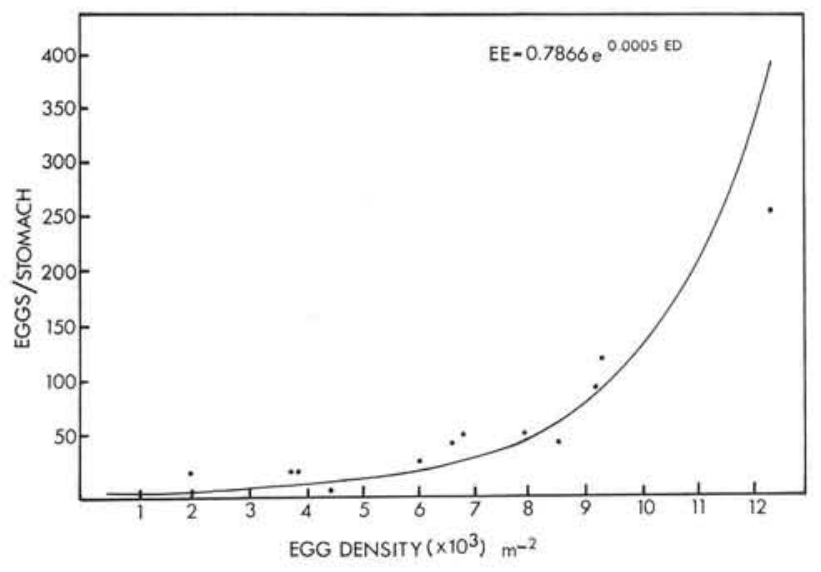

Fig. 3. Engraulis capensis. Functional relationship between anchovy egg density and anchovy egg consumption rate by individual fish (modified after Valdés 1986)

eggs in intraguild predator stomachs and the local density of eggs in the water column.

This relationship shown in Fig. 3 was presented by Valdés et al. (1987) in somewhat different form and was statistically tested to be a non-linear function or density-dependent response. At an egg density higher than $12000 \mathrm{~m}^{-2}$ the egg consumption rate must eventually become limited by handling time and stomach evacuation rate (Peterman 1977). Therefore, the curve shown in Fig. 3 will eventually reach an asymptote to become similar to the sigmoid (Type III) curve of Holling (1959). After the plateau is reached all response levels off because the predator becomes satiated and/or runs out of time in which to eat more prey (Murdoch \& Oaten 1975). The shape of the curve in Fig. 3 might vary (shift towards right or left) according to the relative densities of eggs and other planktonic food organisms, such as copepods, which make up the bulk of the diet of anchovy and possibly also sardine when available (James 1988).

However, from dietary analyses performed on sardines caught during the peak spawning period of anchovy, when secondary production seems to be low, it was found that phytoplankton was more abundant than zooplankton in the sardines' stomachs, and its presence could be related to the presence of anchovy eggs (Valdés unpubl.). From Fig. 4 it is clear that densities of spawning anchovy tend to be highest over the mid-shelf region of the western Agulhas Bank. Nevertheless the abundance and production of copepods there are low because of deep thermoclines and the resultant low primary production. Hence, rates of cannibalism and predation on clupeoid eggs are likely to be highest in this region. Furthermore, because sardine filter larger volumes of seawater than 


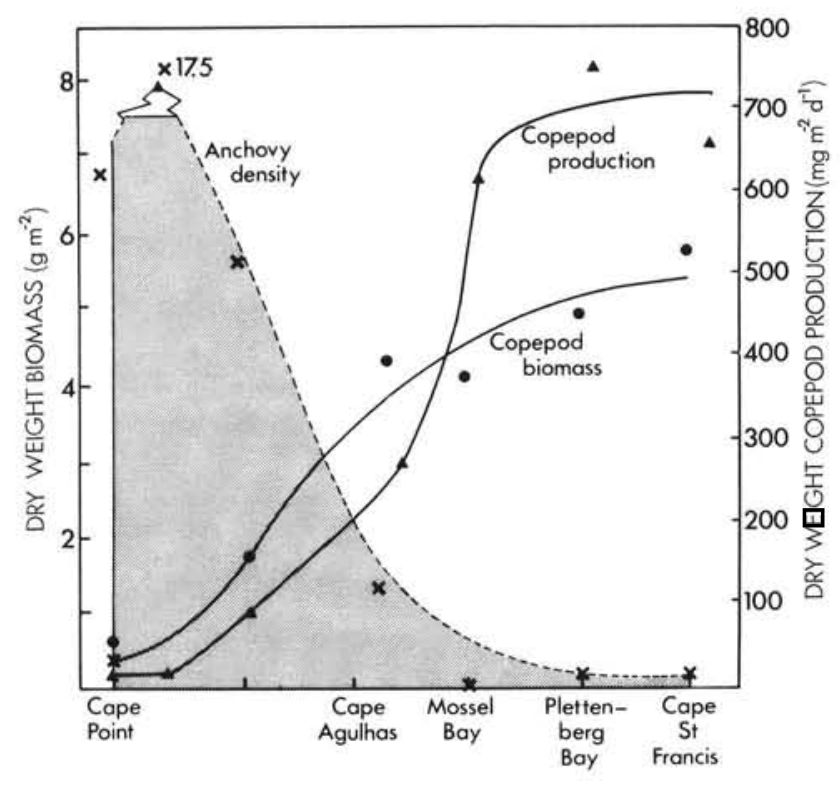

Fig. 4, Engraulis capensis. Anchovy density in the Benguela system and the availability of alternative prey items (modified after Peterson \& Hutchings 1989)

anchovy, if their response is similar to that described by Hollings' (1959), their potential to prey on anchovy eggs in certain areas (i.e. over the western Agulhas Bank) is likely to cause greater mortality of anchovy eggs than cannibalism by anchovies.

The data given in Table 1 show that sardine predation is more destructive to anchovy eggs than anchovy cannibalism at stations where both species co-occur. However, the overall impact of sardine predation on anchovy eggs may depend on both anchovy egg density and the predator's numerical response (Murdoch 1969, Murdoch et al. 1975).

The vulnerability of larvae of Cape anchovy and northern anchovy to cannibalism was investigated by Brownell (1985) and Folkvord \& Hunter (1986) respectively and found to be an important source of mortality. Butler \& Pickett (1988) discussed predation by adult northern anchovy on Pacific sardine larvae and its implication in recruitment variability. Adult Cape anchovy have also been found to prey on sardine eggs (Valdés unpubl.). The importance of such predation at times when the sardine biomass is higher than anchovy depends on whether compensatory mortality similar to anchovy cannibalism and sardine predation on anchovy eggs operates or not in the sardine. If intraguild predation by anchovy on sardine eggs is density-dependent and sardine cannibalism occurs and is also density-dependent, such compensatory mecahnisms in both species may explain long-term clupeoid fluctuations in the Benguela and similar ecosystems.
However, quantitative information on anchovy predation on sardine eggs and sardine cannibalism is difficult to obtain at present given the low biomass of sardine relative to anchovy, the more protracted spawning season of sardine (Le Clus 1979), and because during the months of November, when sampling was conducted for this study, spawning of sardine was not at its peak (Le Clus 1979, Shelton 1986). Furthermore, there is as yet no information on egg production rates of the South African pilchard or sardine. Although fecundity of this sardine might be similar to that of the Namibian sardine (Le Clus 1979), there is no conclusive information currently available for number of spawnings of any of them. In addition, the larger size of sardine eggs relative to anchovy eggs might cause anchovy consumption by particulate feeding (James 1987). Consequently, a particulate feeding model rather than a filtration model would apply to predation of sardine eggs by anchovy and hence to a potential density-dependent mechanism of compensatory mortality.

The overall consumption of anchovy eggs by sardines in 1986 was 3 times greater than by anchovy, even though sardine biomass was an order of magnitude lower than anchovy biomass (Table 2). In 1987 , the rate of anchovy cannibalism increased whereas that of sardine predation decreased. Then, in 1988, the proportion of the anchovy egg production consumed by sardines sharply increased whereas that by cannibalism dropped as shown in Table 2. Therefore, it seems that the frequencies of cannibalism and intraguild predation change according to the relative abundances of the predator and the prey species, their concentrations and the extent of their habitat overlap.

Valdés Szeinfeld (1990) estimated the index of overlapping between anchovy and sardine to be $0.70,0.66$ and 0.58 for 1986, 1987 and 1988 respectively. Anchovy concentration was estimated by the same author as $1.19,0.84$ and 0.93 and the concentration of sardine as $1.27,0.90$ and 1.00 for 1986, 1987 and 1988 respectively. Accordingly, because in 1986 the index of overlapping was relatively high and the concentration of both species was also relatively higher than in 1987 and 1988, it was expected that predation by sardine would predominate over anchovy cannibalism in 1986 more than in 1987 and 1988. Estimates shown in Table 2 supported this expectation: namely $12 \%$ of the total anchovy egg mortality was caused by sardine predation and $4 \%$ by cannibalism in 1986. According to the concentration of both species, it was expected to find higher values of sardine predation on anchovy eggs where both species co-occurred in 1986 (because in these areas, sardine predation probably operates mainly as a compensatory mortality) than in 1987 or 1988. The average number of anchovy eggs found per 
$\mathrm{kg}$ of sardine mass (1988 eggs) was indeed relatively higher than in 1987 (Table 1).

In 1987, both the species overlap index and the concentration of each species decreased. Therefore, sardine predation was expected to be relatively less influential in comparison with anchovy cannibalism as a source of egg mortality than it was in 1986. The percentages of anchovy egg mortality caused by sardine predation and anchovy cannibalism were 8 and $6 \%$ respectively in 1987, as shown in Table 2 . According to the concentration of the species, predation by sardine should have been lower at places of co-occurrence in 1987 than in 1986. The average number of anchovy eggs found per $\mathrm{kg}$ of sardine was 549 (Table 1), almost 4 times lower than in 1986.

In 1988, the index of overlapping was the lowest of the 3 years, but there was a higher concentration of both species than in 1987 (still lower than in 1986). In 1988 there seems to have been an exponential increase in sardine abundance SFRI unpubl.). Despite the lower overlap, the effect of the concentration of predators in specific areas, considering the probable densitydependent nature of sardine predation on anchovy eggs, means that higher values of sardine predation than in 1987 and 1986 were anticipated. The percentage of total anchovy egg mortality caused by sardines was $56 \%$ (Table 2). Because a densitydependent sardine predation response is influenced by both increased density of prey (i.e. anchovy eggs) and density of predators (i.e. sardine), the actual number of anchovy eggs per $\mathrm{kg}$ of sardine found in 1988 was higher than in either of the previous 2 years (3189 eggs; Table 1). The percentage of anchovy egg production consumed by sardines in 1988 had risen to $28 \%$ compared to $6 \%$ and $4 \%$ in 1986 and 1987 respectively (Table 2 ).

In conclusion, results have indicated that, to assist in managing such dynamic resources as the sardine and the anchovy, it may be appropriate to monitor the diet of both species to assess the survival of their respective embryonic stages when subjected to sardine predation or anchovy cannibalism. The anchovy stock-recruitment relationship may be strongly dome-shaped because of cannibalism in some areas (Valdés et al. 1987). However, cannibalism alone cannot be the sole mechanism affecting abundance of anchovy (Smith et al. 1989), and it may be scarcely noticeable as a cause of variation in the presence of the known environmental variability (MacCall 1983). With the size of the sardine stock increasing, both intraspecific and interspecific predation probably have a synergistic effect, causing fluctuations in anchovy recruitment and, hence, in anchovy stock size. Together, they may well be major causes of cycles in clupeoid abundances in the Benguela system.
Acknowledgements. The manuscript was greatly improved in style and content by careful reviews kindly provided by Drs A. I. L. Payne (SFRI), Charles Brownell (Oceanographic Institute, Hawaii), Prof. Polis (Vanderbilt University, Tennessee), Dr J. Alheit (Polarmar, Bremerhaven) and by my supervisor Prof. Charles Griffiths (UCT). Comments provided by Dr K. Cochrane (SFRI) and 2 anonymous reviewers are also acknowledged. This paper is a part of a dissertation submitted in partial fulfilment of the requirements of a Ph.D. degree at the University of Cape Town.

\section{LITERATURE CITED}

Alheit, J. (1987). Egg cannibalism versus egg predation: their significance in anchovies. In: Payne, A. I. L., Gulland, J. A., Brink, K. H. (eds.) The Benguela and comparable ecosystems. S. Afr. J. mar. Sci. 5: 467-470

Armstrong, M. J., James, A. G., Valdés Szeinfeld, E. S. (in press). Estimates of annual consumption of food by anchovy and other fish species off South Africa during the period 1984-1988. S. Afr. J. mar. Sci. 11

Armstrong, M. J., Shelton, P. A., Hampton, I., Jolly, G., Melo, Y. C. (1988). Egg production estimates of anchovy biomass in the southern Benguela system. Rep. Calif. coop. oceanic Fish. Invest. 29: 137-157

Brownell, C. L. (1985). Laboratory analysis of cannibalism by larvae of the Cape anchovy Engraulis capensis. Trans. Am. Fish. Soc. 114(4): 512-518

Butler, J. L., Pickett, D. (1988). Age-specific vulnerability of Pacific sardine, Sardinops sagax, larvae to predation by northern anchovy, Engraulis mordax. Fish. Bull. Wash. 86(1): 163-167

Caswell, H. (1978). Predator-mediated coexistence: a nonequilibrium model. Am. Nat. 112 (983): 127-154

Folkvord, A., Hunter, J. R. (1986). Size-specific vulnerability of northern anchovy, Engraulis mordax, larvae to predation by fishes. Fish. Bull. Wash. 84: 859-869

Fox, L. R. (1975). Cannibalism in natural populations. Ann. Rev. Ecol. Syst. 6: 87-106

Holling, C. S. (1959). The components of predation as revealed by a study of small-mammal predation of the European pine sawfly. Can. Ent. 91: 293-320

Hunter, J. R., Kimbrell, C. A. (1980). Egg cannibalism in the northern anchovy, Engraulis mordax. Fish. Bull. Wash. 78(3): $811-816$

James, A. G. (1987). Feeding ecology, diet and field-based studies on feeding selectivity of the Cape anchovy Engraulis capensis Gilchrist. In: Payne, A. I. L., Gulland, J. A., Brink, K. H. (eds.) The Benguela and comparable ecosystems. S. Afr. J. mar. Sci. 5: 673-692

James, A. G. (1988). Are clupeid microphagists herbivorous or omnivorous? A review of the diets of some commercially important clupeids. S. Afr. J. mar. Sci. 7: 161-177

Jarre, A., Palomares, M. L., Soriano, M. L., Sambilay, V. C., Pauly, D. (1991). Some improved analytical and comparative methods for estimating the food consumption of fishes. In: Daan, N., Sissenwine, M. P. (eds.) Actes du Symposium on Multispecies Models Relevant to Management of Living Resources, The Hague, Netherlands, October 1989. ICES mar. Sci. Symp. 193: 99-108

Lasker, R., MacCall, A. D. (1983). New ideas on the fluctuations of the clupeoid stocks off California. In: Canadian National Committee/Scientific Committee on Oceanic Research (ed.) Proc. Joint Oceanographic Assembly, Halifax, August 1982: General Symposia. Dept of Fisheries and Oceans, Sci. Inf. Publ. Branch, Ontario, p. 110-120 
Le Clus, F. (1979). Oocyte development and spawning frequency in the South West African pilchard Sardinops ocellata. Fish. Bull. S. Afr. 12: 53-68

MacCall, A. D. (1981). The consequences of cannibalism in the stock-recruitment relationship of planktivorous pelagic fishes such as Engraulis. In: Sharp, G. D. (ed.) Report and supporting documentation of the workshop on the effects of environmental variation on the survival of larval pelagic fishes, Lima, 1980. I.O.C. Workshop Rep. 28, Unesco, Paris, p. 201-220

MacCall, A. D. (1983). Variability of pelagic fish stocks off California. In: Sharp, G. D., Csirke, J. (eds.) Proceedings of the expert consultation to examine changes in abundance and species composition of neritic fish resources, San Jose, Costa Rica, April 1983. F.A.O. Fish. Rep. 291(2): 101-112

Moser, H. G., Ahlstrom, E. H. (1985). Staging anchovy eggs. In: Lasker, R. (ed.) An egg production method for estimating spawning biomass of pelagic fish: application to the northern anchovy, Engraulis mordax. Tech. Rep. NOAA NMFS 36: 37-41

Murdoch, W. W. (1969). Switching in general predators: experiments on predator specificity and stability of prey populations Ecol. Monogr. 39: 335-354

Murdoch, W. W., Avery, S., Smyth, M. E. B. (1975). Switching in predatory fish. Ecology 10: 338-342

Murdoch, W. W., Oaten, A. (1975). Predation and population stability. Adv. ecol. Res. 9: 1-385

Peterman, R. M. (1977). A simple mechanism that causes collapsing stability regions in exploited salmonid populations. J. Fish. Res. Bd Can. 34: 1130-1142

Peterman, R. M., Gatto, M. (1978). Estimation of functional responses of predators on juvenile salmon. J. Fish. Res. Bd Can. 35: 797-808

Peterson, W. T., Hutchings, L. (1989). Chlorophyll, particle spectra, zooplankton biomass and production in relation to hydrography and anchovy spawners on the Agulhas Bank. In: Krohn, R. (ed.) Proceedings of the plankton dynamics mini-symposium, Cape Town, South Africa, May 1989. University of Cape Town, B.E.P. Rep., 17: 81-95

Polis, G. A., Myers, A., Holt, R. D. (1989). The ecology and evolution of intraguild predation: potential competitors that eat each other. A. Rev. Ecol. Syst. 20: 297-330

Ricker, W. E. (1958). Handbook of computations for biological statistics of fish populations. Bull. Fish. Res. Bd Can. 119: $300 \mathrm{pp}$

Ricker, W. E. (1973). Linear regressions in fishery research. J. Fish. Res. Bd Can. 30(3): 409-434

This article was presented by J. G. Field, Rondebosch, South Africa
Santander, H., Alheit, J., MacCall, A. D., Alamo, A. (1983). Egg mortality of the Peruvian anchovy Engraulis ringens caused by cannibalism and predation by sardines Sardinops sagax. In: Sharp, G. D., Csirke J. (eds.) Proceedings of the expert consultation to examine changes in abundance and species composition of neritic fish resources, San Jose, Costa Rica, April 1983. F.A.O. Fish. Rep. 291(3): $1012-1025$

Shannon, L. V., Crawford, R. J. M., Brundrit, G. B., Underhill, L. G. (1988). Responses of fish populations in the Benguela ecosystem to environmental change. J. Cons. int. Explor. Mer 45(1): 5-12

Shelton, P. A. (1986). Fish spawning strategies in the variable southern Benguela Current region. Ph.D. thesis, University of Cape Town, South Africa

Smith, P. E., Flerx, W., Hewitt, R. P. (1985). The CalCOFI vertical egg tow (CalVET) net. In: Lasker, R. (ed.) An egg production method for estimating spawning biomass of pelagic fish: application to the northern anchovy, Engraulis mordax. Tech. Rep. NOAA NMFS 36: $27-32$

Smith, P. E., Santander, H., Alheit, J. (1989). Comparison of the mortality rates of Pacific sardine Sardinops sagax, and Peruvian anchovy, Engraulis ringens, eggs off Peru. Fish. Bull., Wash. 87: 497-508

Valdés, E. (1986). Egg cannibalism by anchovy in the southern Benguela Current region. M.Sc. thesis, University of Cape Town

Valdés, E. S., Shelton, P. A., Armstrong, M. J., Field, J. G. (1987). Cannibalism in South African anchovy: egg mortality and egg consumption rates. In: Payne, A. I. L., Gulland, J. A., Brink, K. H. (eds.) The Benguela and comparable ecosystems. S. Afr. J. mar. Sci. 5: 613-622

Valdés Szeinfeld, E. S. (1990). Abundance and mortality of anchovy eggs caused by cannibalism and intraguild predation, and the potential effect on anchovy recruitment and clupeoid fluctuations. Ph.D. thesis, University of Cape Town

Walters, C. J., Stocker, M., Tyler, A. V., Westrheim, S. J. (1986). Interaction between Pacific cod Gadus macrocephalus and herring Clupea harengus pallasi in the Hecate Strait, British Columbia. Can. J. Fish. aquat. Sci. 43(4): 830-837

Welch, D. W. (1986). Identifying the stock-recruitment relationship for age-structured populations using timeinvariant matched linear filters. Can. J. Fish. aquat. Sci. 43: $108-123$

Manuscript first received: June 21, 1991

Revised version accepted: November 15, 1991 